\title{
EDITORIAL
}

\section{REALIDAD DE LOS POSGRADOS EN COLOMBIA Y SU SITUACIÓN FRENTE A LA REFORMA DE LA LEY 30}

\author{
Germán Anzola Montero
}

Rector

El tema que anuncia el precedente titular, refleja nuestra inquietud por abordar un sistema de educación de gran actualidad y de enormes proyecciones para el futuro.

No en balde, hoy día no se concibe que existan estudiantes sin esta distinción que los diferencie de quienes sólo han adquirido la formación educativa básica de carácter superior, dadas sus implicaciones en el mercado laboral $y$, en general, por las connotaciones que una situación de estas características representa.

A diferencia de otros países, incluidos los de Latinoamérica y Europa, en Colombia, el incremento de los posgrados se ha consolidado en las especializaciones. Así lo indican las estadísticas registradas por el Ministerio de Educación Nacional para el 2010, según, las cuales, el país cuenta con 6.059 Especializaciones, frente a 216 programas de Doctorado y 1.076 de Maestría.

Caso contrario es lo obtenido en otros países de América Latina, como Chile, México, Argentina y Brasil, para no hablar de Estados desarrollados, donde las Maestrías y los Doctorados tomaron impulso y se consolidaron y donde las Especializaciones ni siquiera han desempeñado un papel importante, quedando rezagadas a un tercer plano.

Ante esta panorámica, vale la pena preguntarnos, ¿Qué pasa con la formación avanzada en Colombia? Es claro que los posgrados, aparte de ser pocos en el país, son costosos y presentan problemas de mediana o baja calidad, puesto que de todos los programas de Doctorado, solamente uno tiene Acreditación de Alta Calidad y en Maestrías y en Especializaciones, ninguno y con Registro Calificado: 774 para Maestrías; 129 para Doctorados y 3.037 para Especializaciones.

Y es claro, especialmente, por las condiciones económicas de los profesionales colombianos, quienes con dificultad pueden acceder a una Especialización, pues los indicadores del Ministerio así lo reflejan. En efecto, en el 2002, el 6,21\% (aproximadamente, 62 mil personas), se matric- ularon a la alta formación (350, para Doctorado; 55.023, para Especialización y 6.776, para Maestría), mientras que en el 2010, alrededor de 96 mil profesionales (5,73\%), lo lograron (2.392 para Doctorado, 70.247 para Especialización y 24.309 para Maestría). Estas cifras demuestran que Colombia es uno de los países con menos estudiantes de postgrado, cuando su auge está por encima de lo esperado, en otras palabras, es una situación que refleja los problemas de esta oferta interna. En general, el 3,1\% de los colombianos tienen posgrado y, además, reporta el Ministerio, que en los últimos 45 años, únicamente el 18\% de los profesionales consiguieron cursar un programa de éstos en el país.

Pero si se analiza el caso de profesionales con Doctorado y con Maestría, la situación es diciente; a pesar de haberse elevado el número de egresados en los últimos años, las estadísticas siguen siendo muy bajas, comparadas con otros países. Por ejemplo, en el 2008, en Colombia, 118 personas lograron graduarse en Doctorado y 3.411 en Maestría; en el 2009, 173 y 4.740 y, en el 2010, 202 y 5.797 , respectivamente, que comparado con otras naciones, este porcentaje cubre un $34,4 \%$, para Doctorado y un 51,2\%, para Maestría.

Especialistas en el tema señalan, como causas destacadas para llegar a esta situación, las siguientes: 1) Alto costo en las matrículas; 2) Baja calidad académica; 3) Solamente existen en las grandes ciudades y no en las regiones; 4) Baja remuneración en el mercado laboral; 5) No se ofrecen mayores alternativas de crédito y 6) Los programas ofrecidos no son los que se necesitan.

En este orden de ideas es pertinente hacer la comparación entre la normatividad vigente y lo que se propone:

De Ley 30 de 1992:

"ARTÍ́CULO 10. Son programas de postgrado las especializaciones, las maestrías, los doctorados y los post doctorados. ARTícULO 11. Los programas de especialización son aquellos que se desarrollan con posterioridad 
a un programa de pregrado y posibilitan el perfeccionamiento en la misma ocupación, profesión, disciplina o áreas afines o complementarias. ARTícULO 12. Los Programas de maestría, doctorado y post-doctorado tienen a la investigación como fundamento y ámbito necesarios de su actividad. Las maestrías buscan ampliar y desarrollar los conocimientos para la solución de problemas disciplinarios, interdisciplinarios o profesionales y dotar a la persona de los instrumentos básicos que la habilitan como investigador en un área específica de las ciencias o de las tecnologías o que le permitan profundizar teórica y conceptualmente en un campo de la filosofía, de las humanidades $y$ de las artes. PARÁGRAFO. La maestría no es condición para acceder a los programas de doctorado. Culmina con un trabajo de investigación. ARTícULO 13. Los programas de doctorado se concentran en la formación de investigadores a nivel avanzado tomando como base la disposición, capacidad y conocimientos adquiridos por la persona en los niveles anteriores de formación. El doctorado debe culminar con una tesis".

\section{Del Proyecto de Ley, presentado ante el Congreso:}

"ARTícULO 63. Los programas de posgrado son aquellos que se desarrollan con posterioridad a un programa de grado y comprenden los niveles de formación de especialización, maestría y doctorado. ARTícULO 64. Los programas de especialización tienen como propósito la profundización en los saberes propios de un área de la ocupación, disciplina o profesión de que se trate, el desarrollo de competencias específicas para su perfeccionamiento y una mayor cualificación para el desempeño laboral. ARTícULO 65. Los programas de maestrías tienen como propósito ampliar y desarrollar los conocimientos para la solución de problemas disciplinares, interdisciplinares o profesionales y dotar a la persona de competencias que le permitan profundizar teórica y conceptualmente en un campo del saber. Las maestrías pueden ser de profundización o de investigación o abarcar las dos modalidades. Las maestrías de investigación enfatizarán en la formación teórica y en el uso, interpretación y evaluación de investigaciones. Esas maestrías incluirán el desarrollo de competencias científicas y una formación en investigación o creación. Las maestrías de profundización enfatizarán en la formación teórica y práctica del estudiante, dotándolo de competencias orientadas hacia un desempeño profesional de alta calificación con niveles de profundización teórica superiores a los de la especialización. PARÁGRAFO: Las especializaciones médico-quirúrgicas tendrá el nivel de una maestría, y cuando involucren la formación investigativa, el de un doctorado según el concepto que para tal efecto expida la Comisión Nacional de Aseguramiento de la Calidad de la Educación Superior, CONACES. ARTí́CULO 66. Los programas de doctorado tienen como propósito la formación de investigadores con capacidad de realizar y orientar en forma autónoma procesos académicos e investigativos en un área específica del conocimiento y desarrollar, afianzar o profundizar competencias propias de este nivel de formación. Los resultados de las investigaciones de los estudiantes de este nivel de formación deben contribuir al avance en la ciencia, la tecnología, las humanidades o las artes y deben reflejarse en una tesis doctoral. Los programas de doctorado sólo podrán ser desarrollados por las Universidades y por las Instituciones de Educación Superior que cuenten con Acreditación Institucional de Alta Calidad, de acuerdo con el Sistema de Calidad de la Educación Superior".

Como se puede observar, según la Ley 30 , los Post-Doctorados son considerados como un nivel de formación avanzada, lo cual, a nuestro entender, NO puede ser y así se comprende, oportunamente, con el Proyecto de Reforma de Ley. Por otro lado, siempre han existido serios lineamientos para Maestrías y para Doctorados, pero nunca se han visto con claridad para las Especializaciones, por tal razón, para las instituciones es viable obtener el registro calificado y, por ello, la mayor oferta se centra en las Especializaciones en Colombia. En el 2006, el Ministerio de Educación Nacional expidió el Decreto 1001 (3 de abril de 2006), con la idea de ajustar estos programas de alta formación y así aumentar la oferta de Maestrías y de Doctorados. Según la Ministra de ese entonces, la norma buscaba fortalecer algunas Especializaciones para, posteriormente, convertirlas en Maestrías y así cumplir, en un tiempo no mayor de 15 meses, con ciertos requisitos, para obtener el registro calificado: experiencia de los docentes, impacto del programa en el país e infraestructura. El problema, sin embargo, siempre ha sido la falta de calidad, aspecto que las Universidades reconocen, pero que continúan en la búsqueda de mejorar, puesto que, en la actualidad, se siguen fijando normas de calidad obligatorias.

Entonces, ¿Qué necesita el país? La cantidad de posgrados que se ofrecen en Colombia es poca, teniendo en cuenta que su crecimiento no ha sido tan significativo, en comparación con los existentes en Estados Unidos, en Europa y en algunas Naciones de Latinoamérica. Además, se puede añadir que los ofrecidos por las Universidades no son los que requiere Colombia para su desarrollo, ya que se centran en áreas tradicionales, como Derecho, Salud, Ingeniería, Administración, entre otras y se olvidan de las áreas de Agronomía y de Medio Ambiente.

La U.D.C.A, bajo esta visión, ha contribuido, en menor porcentaje, con dos Maestrías de gran impacto social y económico. Por una parte, la Maestría en Agroforestería Tropical, que en convenio con CORPOICA, quiere formar 
profesionales altamente calificados, que contribuyan a la generación de conocimiento e innovación tecnológica en sistemas agroforestales, como estrategias que permitan hacer un uso eficiente y sostenible de la oferta biofísica en los ecosistemas tropicales del país, mejorar las condiciones económicas y sociales de los territorios y disminuir el impacto antrópico sobre los recursos naturales, con miras a cerrar la brecha y la inequidad de la sociedad del medio rural. Y por otra, la Maestría en Ciencias Ambientales, cuyo propósito es formar, a nivel avanzado, investigadores que aborden los problemas ambientales, a partir del desarrollo de competencias necesarias para el estudio de las relaciones de los seres humanos con su entorno natural y formular propuestas de prevención y de solución a las dificultades que, en este campo, se requieren, a partir de un enfoque científico, interdisciplinario, transdisciplinario, sistémico, complejo y abierto al diálogo con otros saberes y con todos los sectores. Como se puede advertir, éste es un aporte fundamental de la U.D.C.A como corresponsable social y ambiental para contribuir, favorablemente, a sortear la crisis ambiental del mundo y del país.

La percepción general de los posgrados, infortunadamente, no corresponde a las necesidades del país sino a lo que es bueno, útil o rentable $\mathrm{y}$, ante esta disyuntiva, se le suma la carencia de profesores con un alto nivel de formación, por lo cual, los profesionales con Doctorado, no encuentran el respaldo económico y laboral, para desarrollar sus conocimientos.

Analizando el aspecto económico, ¿Cuánto invierte un profesional para cursar un posgrado y ser después bien remunerado? Según estadísticas del Ministerio de Educación Nacional existen módulos de las Especializaciones desde los \$5 millones hasta los \$15 y \$20 millones; Maestrías (con una duración dos años), las hay desde los $\$ 8$ y $\$ 9$ millones, para un total de $\$ 30$ a $\$ 35$ millones y Doctorados (un lapso de tres a cinco años), están alrededor de los $\$ 12$ a $\$ 15$ millones, para un total de $\$ 60$ millones. Por estas razones, un gran número de profesionales prefieren formarse fuera del país, puesto que en Colombia es costoso un posgrado de alto nivel; en cambio, en el exterior, se puede hacer sin costo alguno, en Universidades de Francia, de Alemania y de otros países europeos.

Entonces, ¿Quién tiene acceso a esta formación?, ¿Qué tipo de cobertura académica le podemos brindar a los profesionales colombianos? Las universidades reconocen to- dos estos problemas y consideran que las normas expedidas por el Ministerio se deben adoptar, ya que ayudarán a elevar los niveles de calidad, pero mientras no exista una unión entre las Instituciones de Educación Superior en la oferta de sus programas y se cree una sana y leal competencia, seguirá existiendo esa brecha entre los niveles de alta formación y de elevado costo y que, obviamente, afectará al país, puesto que solo podrá brindar programas de baja calidad.

En resumen, las Maestrías y los Doctorados, se constituyen en los niveles de educación que deben promover la formación de excelentes investigadores, con el propósito de incrementar la capacidad investigativa, científica y tecnológica del país. Para su fortalecimiento y su consolidación es necesario cumplir con ciertos referentes, la mayoría de ellos, de carácter internacional: 1) Consolidación de proyectos de investigación; 2) Infraestructura de programas; 3 ) Movilidad de investigadores nacionales y extranjeros y 4) Financiación a estudiantes.

En consecuencia, la ya mencionada reforma a la Ley de Educación Superior debe cumplir con objetivos fundamentales y claros e implementar acciones que conlleven a mejorar la calidad de los posgrados en el país para, Primero: Generar condiciones para una óptima oferta en alta formación y que garantice el mejoramiento de la calidad de los postgrados, en conjunto con el fortalecimiento de la autonomía y la autorregulación de las Instituciones de Educación Superior; Segundo: Propiciar métodos para que un mayor número de profesionales puedan ingresar a los posgrados y se logren graduar, es decir, promover el acceso equitativo, estimular su permanencia, mejorar las fuentes de financiación y fortalecer la participación regional (fuentes de financiación de los recursos del Sistema General de Regalías); Tercero: Acondicionar el Sistema de Educación Superior con la realidad de Colombia y adecuarlo con las tendencias nacionales, regionales e internacionales y Cuarto: Fortalecer los principios de buen gobierno y transparencia en el sector educativo (autonomía institucional y responsabilidad social, en cuanto a la rendición de cuentas ante la sociedad y ante el país).

Este artículo fue elaborado con la colaboración de la Comunicadora Social y Periodista Norella Castro Rojas, Coordinadora de la Oficina de Publicaciones y Patrimonio Intelectual, de la U.D.C.A 